\title{
Marcas de cantero en la Alcazaba de Almería
}

\author{
Stonecutter's marks in the Alcazaba of Almería
}

Manuel María Alonso Ruiz *

\begin{abstract}
RESUMEN
Este trabajo tiene por objetivo recoger y documentar las marcas de cantería de época tardo medieval y moderna que hay en la Alcazaba de Almería. Tras un escueto repaso sobre la Alcazaba tras la conquista castellana de 1489, nos centraremos en la construcción del castillo por mandato de los Reyes Católicos y los canteros que en esta empresa participaron. Por último, ofrecemos los resultados obtenidos a partir de los muestreos efectuados en las cinco zonas de la Alcazaba en que hemos documentado marcas de cantería, y las conclusiones que se pueden extraer.
\end{abstract}

Palabras clave: Alcazaba, Almería, marcas, canteros.

\section{LA ALCAZABA CRISTIANA}

La Alcazaba de Almería ha sido estudiada desde múltiples ámbitos de estudio relacionados con la historia y la arqueología; desde su aparición en las fuentes mayormente islámicas, hasta las excavaciones que en sus recintos se han desarrollado desde los años 40 del pasado siglo, pasando por la evolución arquitectónica de sus zonas, elementos y técnicas constructivas, hallazgos numismáticos y epigráficos, o la comparación a la que se ha visto sometida en alusión a su origen califal con la paradigmática

\begin{abstract}
This paper aims to collect and document the masonsmarks of late medieval and modern times is on the Alcazaba of Almeria. After a brief review on the Citadel after the christian conquest of I489, we will focus on the building of the castle on a mandate from the Catholic Kings and the masons who participated in this endeavor. Finally, we provide the results obtained from sampling in the five areas of the Citadel, where we have documented masons-marks, and the conclusions to be drawn.
\end{abstract}

Key Words: Alcazaba, Almería, marks, stonecutters.

fortaleza de Gormaz, por citar tan solo unos pocos ejemplos, de tal manera que podemos afirmar que en los últimos años las lagunas bibliográficas sobre este Conjunto Monumental se han visto parcialmente superadas !.

No obstante, es necesario aludir a la menor atención de que ha sido objeto el actual tercer recinto de La Alcazaba, el Alcázar de los Reyes Católicos, omitiendo, eso sí, el interés arquitectónico que pueda presentar desde un punto de vista castellológico (Fig. I). Ello puede deberse al hecho de que existe una mayor

\footnotetext{
* Centro de Estudios de Arqueología Bastetana

I El mayor aporte bibliográfico lo constituye la completa obra publicada en 2005 que bajo el título de La Alcazaba; fragmentos para una historia de Almería, englobaba artículos de investigadores de diversos ámbitos de estudio y que suponía un rico compendio que desde un enfoque multidisciplinar, nos acerca al estado actual de las investigaciones sobre La Alcazaba. Existe un trabajo previo sobre los signos lapidarios de la Alcazaba, publicado en 1983 por N. ALBA y A. PORRAS, bajo el título Firmas de los canteros en la Alcazaba de Almería. Se trata de una comunicación emitida un año antes, durante el III Coloquio Internacional de Gliptografía que se celebró en Zaragoza.
} 
información documental referente al mismo, en contraposición al dilatado período andalusí que, aún no estando exento de fuentes, deja a la arqueología como principal encargada de ofrecer hipótesis que establezcan en mayor o menor medida los rasgos propios que definieron la cultura material de los pobladores de la ciudadela durante la Edad Media.

No nos detendremos excesivamente en exponer los sucesos que conducen a la toma de Almería por los Reyes Católicos y lo que acontece en los años inmediatamente posteriores, pues no constituye el objeto de estudio de este artículo, habiendo sido, además, ya tratado en otros trabajos ${ }^{2}$. Sólo diremos de manera escueta, que los Reyes Católicos entran en Almería el 23 de diciembre de 1489 y, ante el ruinoso estado en que encuentran la Alcazaba, acometen sin tardanza una ardua empresa constructiva para refortificarla, así como a la propia ciudad. Esta actividad de fortificación y construcción será, junto al poblamiento, piedra angular para implantar la nueva cultura cristiana en la ciudad y, por ende, en todo el Reino de Granada, siendo personificada en Almería por Gutierre de Cárdenas (de MIGUEL, 2000:103) y concretándose, en el plano militar, mediante la erección de un castillo en el frente occidental de la antigua Alcazaba islámica. Ello obedece a varios motivos: por un lado existe una nueva realidad geoestratégica, ya que a partir de este momento Almería se erigirá en frontera marítima del Mediterráneo frente a las costas de Berbería. Además, estaba el hecho de someter a la población, desde entonces mudéjar, y que no tardaría en manifestar su descontento ante el incumplimiento, por parte castellana, de lo estipulado en la Capitulación del 10 de diciembre de I489 3; para ello, nada mejor que la presencia de un fuerte Alcázar, vigilante e intimidatorio. Otra circunstancia sería la adaptación por parte de la ciudadela a las nuevas exigencias bélicas impuestas por el empleo generalizado de la artillería pirobalística, y que se irá concretando a lo largo del siglo XVI, mediante la construcción de tres baluartes artilleros, a saber: San Matías, La Campana y el Espolón (CARA, 1990:457).

\section{CANTEROS DE LA ALCAZABA}

Acerca de los conocimientos que tenemos en la actualidad sobre lapicidae, artífices, lathomi, operarii o magístrum operae en época medieval, podemos afirmar que la información es escasa para la época del Románico, más abundante a partir del siglo XIII y muy profusa desde el siglo XV (OURSEL, 1987:67). Tenemos constancia de su organización en logias, del secretismo de sus conocimientos (RABASA, 2000:38-39), categorías laborales, especialización técnica, herramientas utilizadas, carácter itinerante e importancia social ${ }^{4}$. En alusión a esta última condición, y a modo de ejemplos, podemos afirmar que su trabajo se define como "...de carácter más noble, y hasta cierto punto culto..." (DACOSTA, 2008:126), o que "...la asociación gremial en la Antigüedad y la Edad Media era un fenómeno común, pero pocos de estos grupos mantuvieron el prestigio social y la influencia posterior como el de los constructores o albañiles." (PUENTE, 2006:I5).

En nuestro caso, el mayor aporte informativo sobre la construcción del castillo de los Reyes Católicos, circunstancias que lo rodearon, personajes que participaron en él directa o indirectamente, presupuestos manejados y

\footnotetext{
2 Dos artículos de referencia sobre el alcázar cristiano y La Alcazaba en época moderna han sido consultados y a ambos se aludirá en mas de una ocasión: el primero publicado en 1990 por Lorenzo Cara, lleva por título "La remodelación de una fortaleza musulmana medieval: la Alcazaba de Almería en época cristiana (siglos XV y XVI)" y el más reciente vio la luz en 2005, en la obra compilatoria antes mencionada, bajo el título "La Alcazaba de Almería y su arquitectura en época cristiana", obra de María del Rosario Torres y María del Mar Nicolás.

3 Recordemos como ya, en el verano de 1490, se produce una primera y confusa revuelta, tras la cual, los mudéjares son expulsados de las ciudades de Almería, Baza, Guadix, Almuñécar y Fiñana; véase DE MIGUEL (2000), SEGURA y TORREBLANCA (I986); a esta primera, siguió una segunda revuelta, que tras comenzar en el Albaicín el 18 de diciembre de 1499, se extendió a la Sierra de Los Filabres y Campo de Níjar en octubre de 1500 (DOMÍNGUEZ y VINCENT, 1997: 19).

4 Todo ello se encuentra desarrollado de una forma amena y muy completa en Los canteros medievales de José Antonio MARTíNEZ PRADES (200I). En este mismo sentido, aunque enfocando el ámbito de estudio sobre el mudéjar hispano y la figura de los albañiles y alarifes bajomedievales, véase Los constructores de la España Medieval de Rafael CÓMEZ (2006).
} 
ejecución de las obras, nos lo proporcionan Torres y Nicolás (2005). De toda la interesante información expuesta en dicho artículo, lo que verdaderamente nos atañe es: por un lado los nombres de canteros facilitados (que será tratado más adelante) y las dos fases constructivas del castillo (que hemos seguido a la hora de efectuar el muestreo de campo y que utilizaremos para la posterior clasificación de las marcas, en las dos zonas en que hemos dividido el castillo); así tendríamos una primera fase que iría desde 1490 hasta I493"...años durante los cuales la actividad constructiva fue constante y en la que se llevó a cabo el núcleo formado por la torre del Homenaje y sus dos cuerpos anejos..." (TORRES y NICOLÁS, 2005: I31) y otra segunda etapa que "...se inició en 1499 para culminar en 1502, y en ella se levantaron los lienzos de muralla y los cubos que rodean el perímetro del castillo, comprendido su patio de armas..." (TORRES y NICOLÁS, 2005: I33).

En cuanto al maestro encargado de acometer las obras del Alcázar, parece que fue Fernán Gómez de Marañón 5: "...personaje nebuloso, la única cosa en concreto que se sabe de él es su nombre. Por eliminación se deduce que fue el maestro de obras del alcázar de Almería, por lo menos entre 1499 y 1502, y probablemente desde 1490..." y "...por correspondencia de una serie de pormenores, se deduce que quien quiera que dirigió las obras de Almería, lo hiciera también en el castillo de Peñafiel, cuya construcción no puede ser posterior a 1466..." (COOPER, I991, I: 52). No obstante, no queda clara la autoría del castillo por parte de dicho constructor, al menos durante la primera fase de las obras: "... en el estado actual de la investigación es imposible aventurar el nombre del maestro responsable de las obras del castillo en esta primera fase, aunque sí se conocen los del mayordomo de las mismas, un tal Garcerán de Almenara, y del veedor de ellas, Juán de Montenegro" (TORRES y NICOLÁS, 2005: 132).

\section{MUESTREO POR ZONAS}

El presente trabajo no pretende ser un estudio de gliptografía propiamente ${ }^{6}$; no es su intención el estudio e interpretación de los signos lapidarios per se. Más bien se trata de reflejar gráficamente, mediante muestreo, las marcas de cantero que existen en las diversas zonas de la Alcazaba de Almería, para tratar de establecer su validez como indicadores cronotipológicos fiables dentro de un mismo conjunto arquitectónico bien definido (AZKARATE, 2002:67).

El estudio, en este caso, se lleva a cabo dentro de un mismo conjunto arquitectónico, (Fig. 2 ) aunque bien pudiera hacerse extensible a otros edificios de ámbito local o provincial, pudiéndose tomar como ejemplo otros dos edificios muy significativos de la arquitectura almeriense del siglo XVI, como son el castillo de Vélez Blanco y la Catedral de Almería, pues ambos cuentan con marcas e inscripciones. Sin duda esta cuestión requeriría de un estudio más amplio, que excede a todas luces el objetivo de este artículo.

A la hora de establecer el muestreo, hemos documentado cualquier inscripción apreciable incisa en caras de sillares o en dovelas de arcos, aún a pesar de que quizás algunas de ellas no merezcan ser consideradas propiamente como marcas de cantero, sino inscripciones de otro tipo, marcas de asiento de sillares o utilitarios.

Es de destacar la variedad de tipos recogidos, su diferente factura y morfología, y la repetición de algunas marcas en las diferentes

5 Desconocemos el origen de dicho maestro, aunque unos pocos años después, si que sabemos que los constructores de la Catedral de Almería, a partir de 1524 eran vascos mayormente (CABRILLANA, 1982: I20), al igual que canteros de ascendencia cantábrica encontramos también en Granada a lo largo del siglo XVI, algunos de ellos establecidos de manera sedentaria en dicha ciudad, como muestran los protocolos notariales (GILA, 2000).

6 Concerniente a la interpretación de las marcas, MARTíNEZ PRADES, (200I): 21 , afirma que la mayor parte de ellas son simplemente firmas de los canteros, que les eran dadas por su logia al alcanzar el grado de oficial o compañero y que servirían para establecer el volumen de trabajo desarrollado, para así recibir el correspondiente estipendio. Otro autor, en cambio, con menos fundamento, afirma que cada marca correspondía a una familia o hermandad, véase PÉREZ, (1974):6I. 
zonas de muestreo ${ }^{7}$, lo cual podría servir también para asignar cronologías a algunas fábricas modernas de dudosa fecha, aunque no nos hemos detenido a enumerar las remodelaciones y obras que sufre La Alcazaba en época moderna, excepción hecha del gran momento que supone la construcción del castillo, y los tres baluartes que simplemente mencionamos con anterioridad (CARA, 1990).

De alguna marca concreta hemos hallado variantes que difieren muy poco entre si y a las que aludiremos posteriormente; otras marcas, sin embargo, han resultado difíciles de documentar, por la erosión y deterioro que presentan actualmente los sillares, mayormente de arenisca.

Cinco han sido las zonas de La Alcazaba que hemos establecido a la hora de efectuar el muestreo:

\section{Lienzo y contrafuerte del primer recinto (Zona I)}

Esta zona está formada por un pequeño lienzo (Fig. 4) y un contrafuerte contiguo (Fig. 3) que se ubican junto a la poterna que da acceso a la muralla de la Hoya. El aparejo que presentan es una sillería de no de mucha calidad, ya que los sillares no están bien tallados ni escuadrados, no mereciendo algunos de ellos ser calificados como tales. A pesar del aglutinante que recubre sus juntas, son apreciables verdugadas de ladrillos (sólo una por hilada) que delimitan y calzan las hiladas de sillares.

Es de destacar la poca calidad de estas marcas, de trazos muy finos, alargados y poco profundos.
Cinco han sido las marcas documentadas, repitiéndose dos de ellas (2 y 4) hasta tres veces (Fig. 5).

\section{Muro de la Vela (Zona 2)}

El Muro de la Vela (Fig. 7) es resultado de las varias intervenciones efectuadas en época moderna y supone la divisoria entre el primer y segundo recinto.

Las marcas han sido tomadas en los paramentos del frente este, en el paño bajo la campana y en los sillares que forman las aristas de la torre. Señalar que no aparecen marcas en todas las caras de sillares ${ }^{8}$ y que un buen número de ellas han sido documentadas mediante prismáticos.

En total, han sido quince las marcas distintas documentadas en esta zona, tras haber muestreado cincuenta individuos. (Fig. 6)

\section{Machones del segundo recinto (Zona 3)}

De esta manera denominamos a dos machones cuadrangulares (Fig. 8.), que se sitúan a ambos lados del itinerario señalizado que discurre por el actual segundo recinto. Están situados unos pocos metros mas arriba de las casas andalusíes restauradas. Solo en uno de ellos, el situado al Norte, o a la derecha del itinerario conforme se asciende, hemos apreciado tres marcas distintas (Fig. 9)

\section{Torre del Homenaje (zona 4) (Fig. I0)}

Sin duda la zona mas prolífica en cuanto a variedad y calidad de las marcas. La mayoría han sido tomadas en el interior de la torre y son apreciables a simple vista. Recordemos

\footnotetext{
7 MARTÍNEZ PRADES, (200I): 34-35, recoge algunos sistemas de clasificación de signos lapidarios, según su origen. En nuestro caso, la sistematización que hemos empleado, se podría ajustar más o menos al método de Van Belle. Este autor, primeramente traza una división entre signos de cantería y graffiti, para a su vez, dividir los de cantería en signos de identidad (firmas de los canteros) y utilitarios (los que se marcaban para facilitar la colocación de los sillares, indicando que posición debían llevar, su orden, altura, etc.). Los graffiti, por último, serían signos o dibujos, generalmente únicos que realizarían personas de paso, vagabundos, prisioneros en sus celdas, etc.

8 A este respecto CÓMEZ (2006): I 32, recoge la opinión de RODRÍGUEZ ESTÉVEZ, Juan Clemente (I 997): Los canteros de la Catedral de Sevilla: del Gótico al Renacimiento. Sevilla, Diputación provincial de Sevilla, al afirmar que "...la ausencia de marcas en muchos sillares le lleva a concluir que fueron realizados por canteros que hacían horas extras cuando lo necesitaba la Fábrica, conviviendo un sistema de jornales en que no se marcan las piedras y el de destajo en el que se dan la mayor parte de ellas." La relación entre sillares firmados y trabajo a destajo, la encontramos presente también en los canteros que trabajaron en la catedral de Huesca hacia I497 (FERRER BENIMELI, 1987:84).
} 
que, según lo expuesto antes, esta zona fue la primera en construirse entre 1490 y | 493.

Se ha realizado el muestreo sobre treinta y ocho caras de sillar, registrándose diecisiete marcas diferentes, donde la marca $n^{\circ} 6$, resulta la más repetida, no solo en esta zona, sino también en todas las demás (Fig. I I).

\section{Torre de la Pólvora (Zona 5) (Fig. 12)}

Las marcas, aquí, han sido documentadas allí donde las dos estancias interiores no han sido restauradas, o sea, en los lienzos anexos y escalerillas que ascienden a la terraza superior. Ya aludimos antes a las fechas de 1499-1503 como las de construcción de esta zona.

Han sido cincuenta y cuatro los individuos muestreados, registrándose un total de trece marcas diferentes. Al igual que en la anterior zona, estas marcas presentan una factura bastante buena, con trazos profundos y regulares, y unas equilibradas proporciones (Fig. I3).

\section{ANÁlisis DEL MUESTREO Y CONCLUSIONES (Fig. I4)}

Sobre un total de ciento cincuenta y cuatro sillares analizados, y cincuenta y tres marcas diferentes, podemos concluir que:

- En el castillo de los Reyes Católicos, y mas concretamente en la Torre del Homenaje, es donde se encuentran los signos lapidarios de mejor factura y calidad, así como de menor tamaño; todos ellos presentan una buena técnica de acabado con trazos profundos y perfectamente definidos. En estos casos, y en varios de los que aparecen en el Muro de la Vela, podemos hablar sin ninguna duda de auténticas marcas de cantero, como signos de identidad o firmas de los mismos. En otros, (como la zona uno) aún presentándonos dudas, han sido recogidas y documentadas, aunque quizás sería más propio hablar de marcas de asiento de sillares, graffiti u otros signos lapidarios de origen incierto. No obstante, podríamos afirmar que por regla general, todas las marcas documentadas en las diferentes zonas son de factura poco compleja y algo toscas?.

- Vemos que algunas marcas se repiten en diferentes zonas:

- por ejemplo la número 22 (zona tres), 29 (zona cuatro) y 49 (zona cinco) es la que más se repite en las dos zonas del castillo analizadas (cuarenta ocasiones), apareciendo también una sola vez en la zona tres, aunque con distinta inclinación. Es la única inscripción que nos aparece en tres zonas distintas. En total encontramos esta marca en cuarenta y una ocasiones, lo que supone un $26,6 \%$ sobre un total de ciento cincuenta y cuatro marcas para las cinco zonas, y un 43,4\% sobre noventa individuos muestreados en las dos zonas del castillo.

- En las zonas uno y dos se repiten dos marcas: I-6 y 5-7.

- Ninguna marca se repite en las zonas uno y tres.

- Una marca 3-30 nos aparece en las zonas uno y cuatro.

- También es una sola marca la que se repite en las zonas uno y cinco: 4-42.

- Ninguna marca se repite en las zonas dos y tres.

- Una marca se repite en las zonas dos y cuatro: 9-26.

- Hay tres marcas que se repiten en el Muro de la Vela (zona dos) y en la Torre de la Pólvora (zona cinco): la número 10-43, | |-48 y |8-4|.

9 El arquitecto Vicente Lampérez y Romea, pionero en España en el estudio de signos lapidarios, sostuvo que "...en los (edificios) de carácter militar, los signos lapidarios son de trazos brutales, de formas caprichosas, y se ven en gran número y variadísimos; mientras que en los edificios religiosos, son de pocos tipos y abundan las cruces y las formas geométricas."LAMPÉREZ (1930):56. 
- En las zonas tres y cuatro solo hay una coincidencia, mencionada anteriormente: 22-29.

- En las zonas cuatro y cinco, aparte de lo expuesto en relación a la marca 29-49, encontramos otras dos coincidencias: $32-45$ y $37-47$.

- Algunas marcas presentan variantes como la supresión o añadido de un segmento. En este caso, sería razonable considerar a los individuos que las tallaron como pertenecientes a una misma confraternidad, o incluso a un mismo grupo familiar: (29, 37,47, 43, 2); (6, 15,20); todas en la zona dos, excepto esta última); $(5,16)$.

- Prevalecen las marcas de carácter geométrico y líneas rectas. Algunas podrían considerarse muy típicas y extremadamente sencillas, asimilables a la iconografía cristiana y a su símbolo más universal como es la cruz; ya sea griega o de brazos iguales (52), de San Andrés ( I I-48), cruz latina invertida bajo peana (35) o un extraño y bonito signo (53). Otros signos se relacionarían con instrumentos de los canteros y la construcción; (9-26), (3-30), (40), (38). También tendríamos otros signos llamativos de interpretación mágica o profiláctica, como el Pentalfa (50) o el Sello de Salomón (32-45); otros signos podrían representar anagramas de nombre propios (25 y 39).

En definitiva podemos sostener, tras el análisis efectuado de las marcas en las distintas zonas, que existe una clara afinidad entre la construcción de la Torre del Homenaje y la Torre de la Pólvora y sus dos lienzos anexos, de tal modo que podríamos hablar de un único momento constructivo para el alcázar de los Reyes Católicos. Ello no implica que dicho momento no se dilatase en el tiempo varios años, y que muchos de los canteros que comenzaron las obras, viesen la culminación de las mismas. Esta hipótesis estaría en consonancia con los datos ofrecidos por las fuentes escritas, y que se encuentra publicado por Torres y Nicolás (2005) y Cooper (1991).
Recordemos cómo estos autores hablaban de dos momentos constructivos en relación al castillo: (1490-93), ( 1499- I 502) separados por un intervalo de seis años, durante los cuales las obras cesaron.

La erección de la mayor parte del Muro de La Vela, se podría adscribir también a los dos momentos constructivos del castillo, en especial al segundo de ellos, cuando se levanta la Torre de la Pólvora y se cierra el perímetro del alcázar por poniente. Aunque hay que reseñar que la sillería aún permanente del muro de La Vela, así como las marcas, presentan una menor calidad respecto a la talla y signos que ofrecen los sillares del castillo. Asimismo, una parte de los paramentos actualmente visibles en dicho muro, está constituida por reformas posteriores.

Más difícil resulta el tratar de asignar cronologías a los elementos constructivos que suponen las zonas uno y tres. Es seguro que su origen estuvo relacionado con la construcción del castillo (alguna marca se repite), aunque en la zona uno, encontremos un aparejo de sillares mal escuadrados, donde se emplea el ladrillo para calzar las hiladas. También en esta zona uno, las marcas son toscas, muy finas y esquemáticas, apenas visibles; muy inferiores en calidad a las que encontramos en el alcázar o en el Muro de la Vela. De considerarlas como marcas de cantero, solución por la que hemos optado, daría la impresión de que los talladores apenas se molestaron en grabar las piedras, o de que esta tarea, junto a la construcción del lienzo y el contrafuerte, le fue encomendada a los aprendices menos expertos, mientras los maestros experimentados y oficiales, reservaron su buen hacer para las partes mas nobles y para aquellas que pudieran ser apreciadas y admiradas a simple vista, pues ésta característica si que se puede sostener, en cuanto a la talla de la piedra y la calidad de las marcas: la fábrica mas elaborada se encuentra en la Torre del Homenaje, auténtico epicentro del castillo, mientras que las marcas mas preciosistas, son las que se observan a simple vista en el interior de dicho reducto. 


\section{BIBLIOGRAFÍA}

ALBA, Narciso y PORRAS, Antonio, (1983): "Firmas de los canteros en la Alcazaba de Almería", Actas del III Coloquio internacional de gliptografía. Zaragoza, pp.599-608.

AZKARATE GARAI-OLAUN, Agustín, (2002): “Intereses cognoscitivos y praxis social en Arqueología de la Arquitectura", Arqueología de la Arquitectura. I, Madrid, CSICI Universidad del País Vasco, pp.55-72.

CABRILLANA, Nicolás, (1982): Almería Morisca. Granada, Universidad de Granada.

CARA, Lorenzo, (1990): "La remodelación de una fortaleza musulmana medieval: la Alcazaba de Almería en época cristiana (siglos XV y XVI)", Almería entre culturas (siglos $X I I I-X V I)$. I. Almería, Instituto de Estudios Almerienses, pp. 453-485.

CÓMEZ, Rafael, (2006): Los constructores de la España Medieval. Sevilla, Secretariado de publicaciones de la Universidad de Sevilla.

COOPER, Edward, (199|): Castillos señoriales en la Corona de Castilla, III. Salamanca, Junta de Castilla y León.

DACOSTA, Arsenio, (2008): "La arquitectura popular y sus autores: estética y dialéctica en la cantería de Nuez de Aliste (Zamora)", Revista de Dialectología y Tradiciones Populares. 63, Madrid, CSIC, pp. 121-142.

DE MIGUEL, Juan Carlos, (2000): “Entre la marginación y la asimilación: moriscos y estructuras de poder en Almería a finales de la Edad Media", Los marginados en el mundo medieval y moderno: Almería, 5 a 7 de noviembre de 1998. Almería, Instituto de Estudios Almerienses, pp. I0 I- 106.

DOMÍNGUEZ ORTIZ, Antonio y VINCENT, Bernard, (1997): Historia de los moriscos. Madrid, Alianza Universidad.

FERRER BENIMELI, José Antonio, (1987): "Notas sobre algunos canteros de la Catedral de Huesca", Homenaje a D. Federico Balaguer Sánchez. Huesca, Instituto de Estudios Altoaragoneses, pp.81-90.
GILA, Lázaro, (2000): Maestros de cantería y albañilería en la Granada Moderna, según los escribanos de la ciudad. Granada, llustre Colegio Notarial de Granada.

LAMPÉREZ, Vicente, (1930): Historia de la arquitectura cristiana española en la Edad Media según el estudio de los elementos y los monumentos, I. Madrid, Espasa Calpe.

MARTÍNEZ PRADES, José Antonio, (200I): Los canteros medievales. Madrid, Akal.

OURSEL, Raymond, (1987): La arquitectura Románica. Madrid, Ediciones Encuentro.

PÉREZ ARRIBAS, Andrés, (1974): "Las marcas de los canteros en los templos románicos y góticos, y su interés actual", Wad-al-Hayara. I, Guadalajara, Diputación provincial de Guadalajara, pp.57-63.

PUENTE, Juán Luis, (2006): Firmado en la piedra por los maestros canteros medievales. León, Edilesa.

QUIRÓS CASTILLO, Juan Antonio, (1996): "Indicadores cronológicos de ámbito local: cronotipología y mensiocronología", Arqueología de la Arquitectura. El método arqueológico aplicado al proceso de estudio y de intervención en edificios históricos. Valladolid, Junta de Castilla y León, pp. $179-187$.

RABASA, Enrique, (2000): Forma y construcción en piedra. De la cantería medieval a la estereotomía del siglo XIX. Madrid, Akal textos de arquitectura.

SEGURA, Cristina y TORREBLANCA, Agustín, (1986): "Notas sobre la revuelta mudéjar de 1490: el caso de Fiñana", En la España Medieval. 9, Madrid, Universidad Complutense, pp. I197-1216.

TAPIA, José Ángel, (1970): Almería piedra a piedra. Vitoria, Monte de Piedad y Caja de Ahorros de Almería.

TORRES, María del Rosario; NICOLÁS, María del Mar, (2005): "La Alcazaba de Almería y su arquitectura en época cristiana", La Alcazaba, fragmentos para una historia de Almería. Almería, Consejería de Cultura de la Junta de Andalucía, pp. 129-148. 


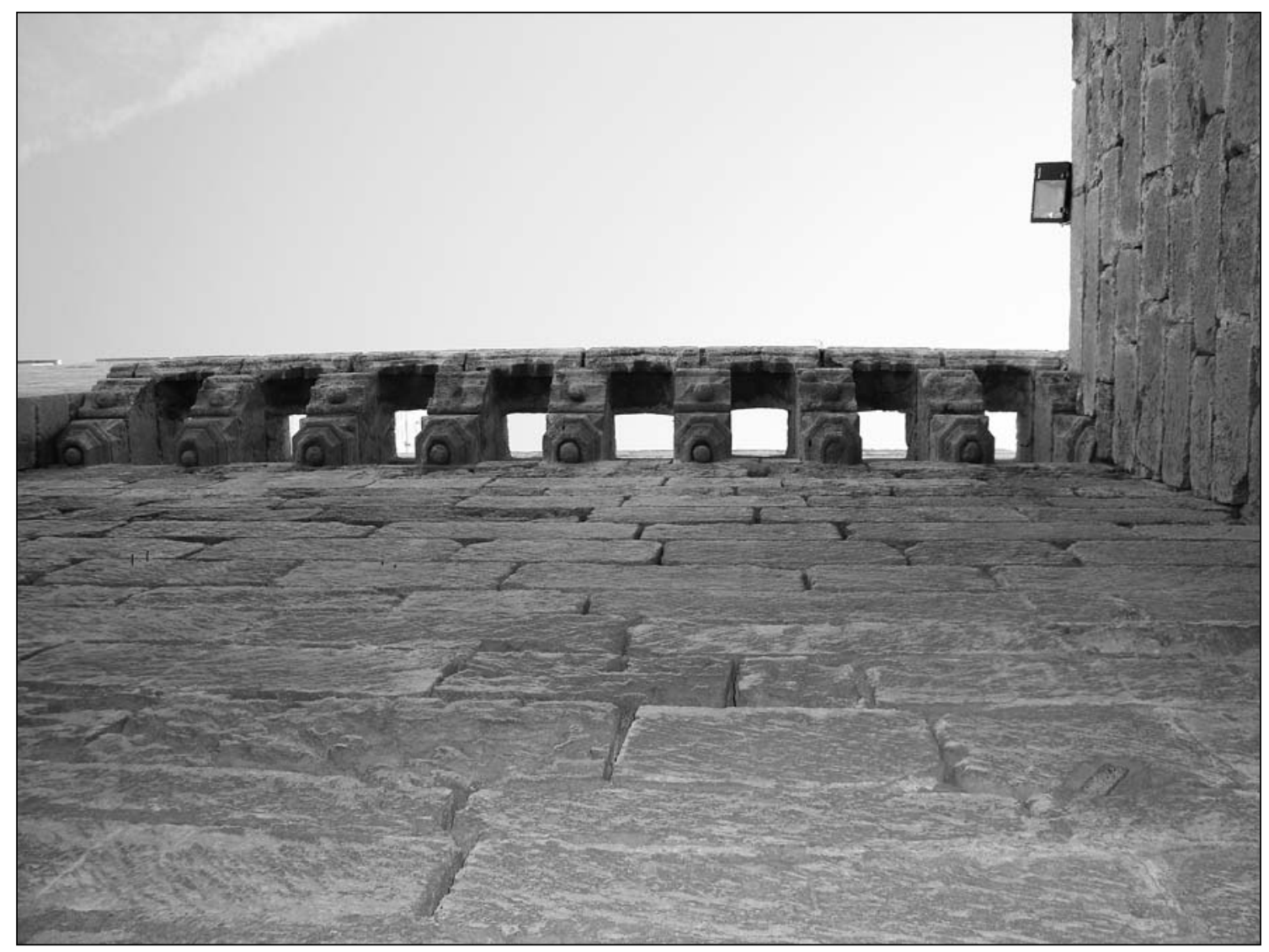

Fig. I. Matacán corrido en la Torre del Homenaje

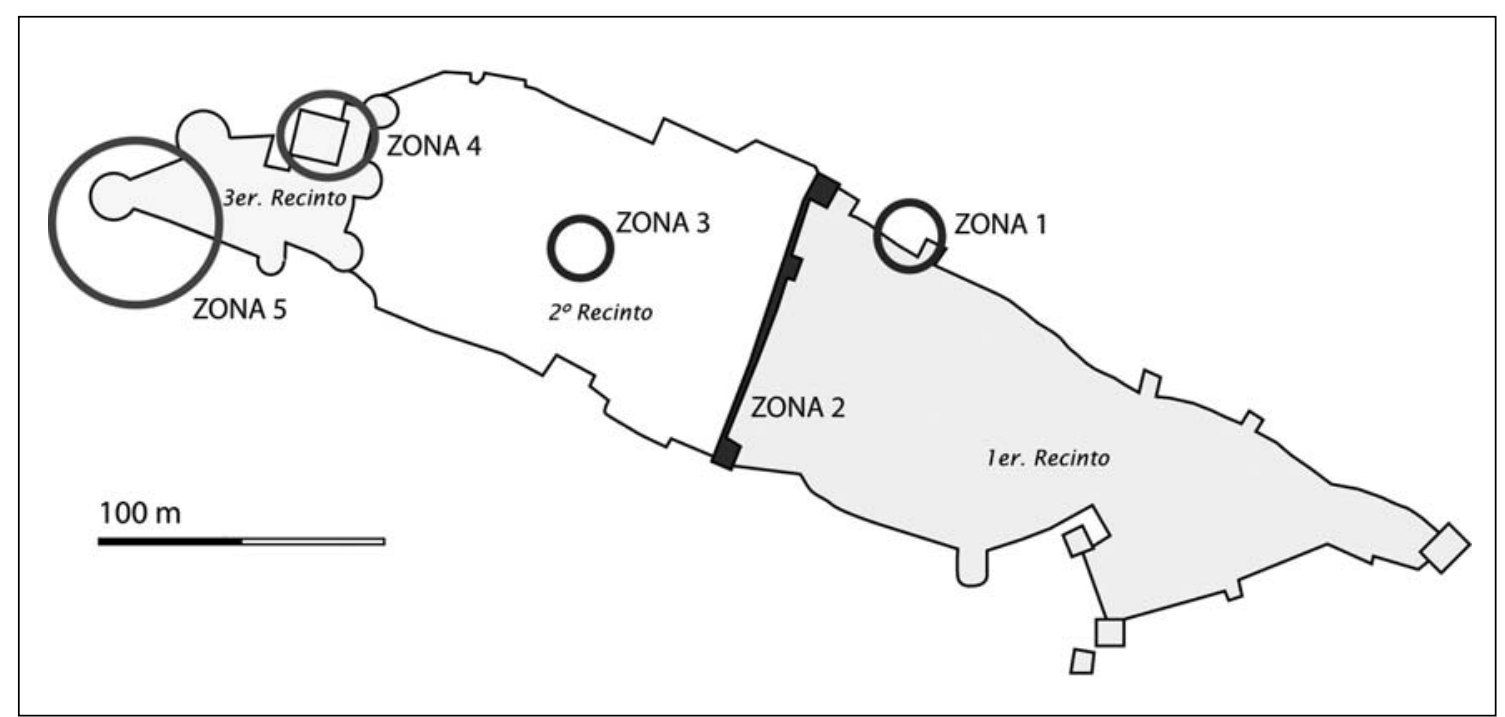

Fig.2. Planta esquemática mostrando los tres recintos del Conjunto Monumental, y las zonas donde se ha efectuado el muestreo. 


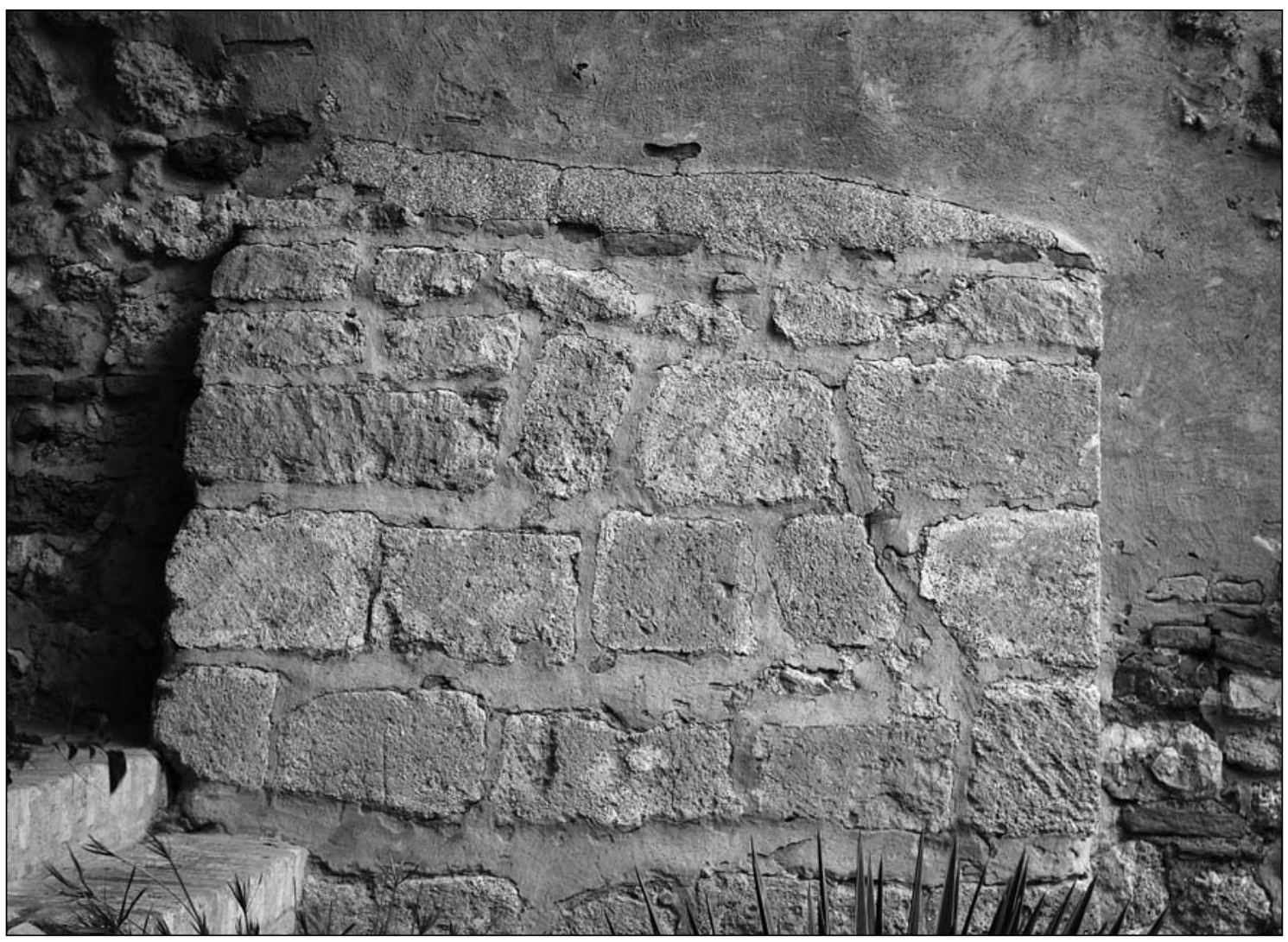

Fig. 3. Contrafuerte. Zona I

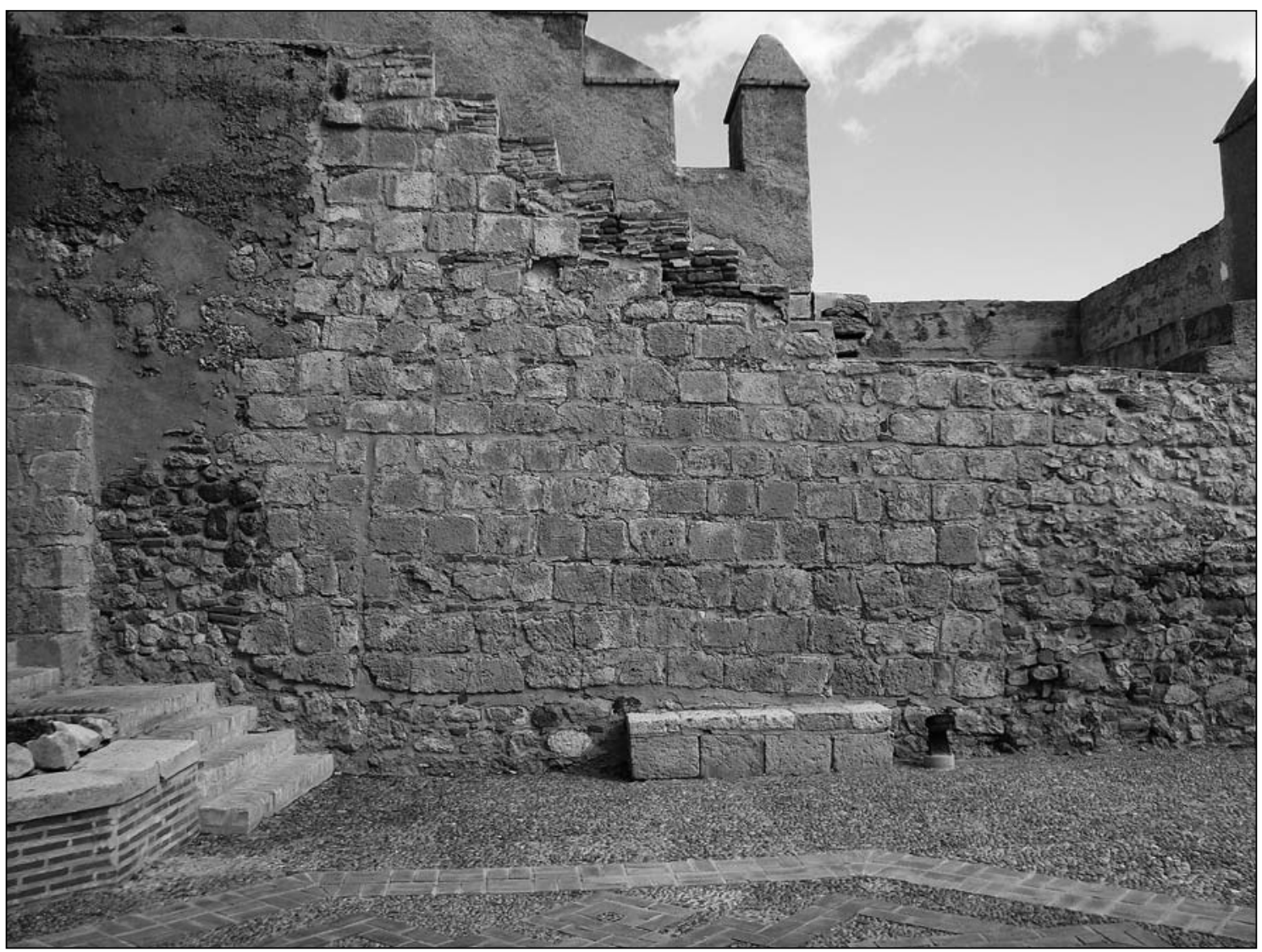

Fig. 4. Lienzo. Zona I 


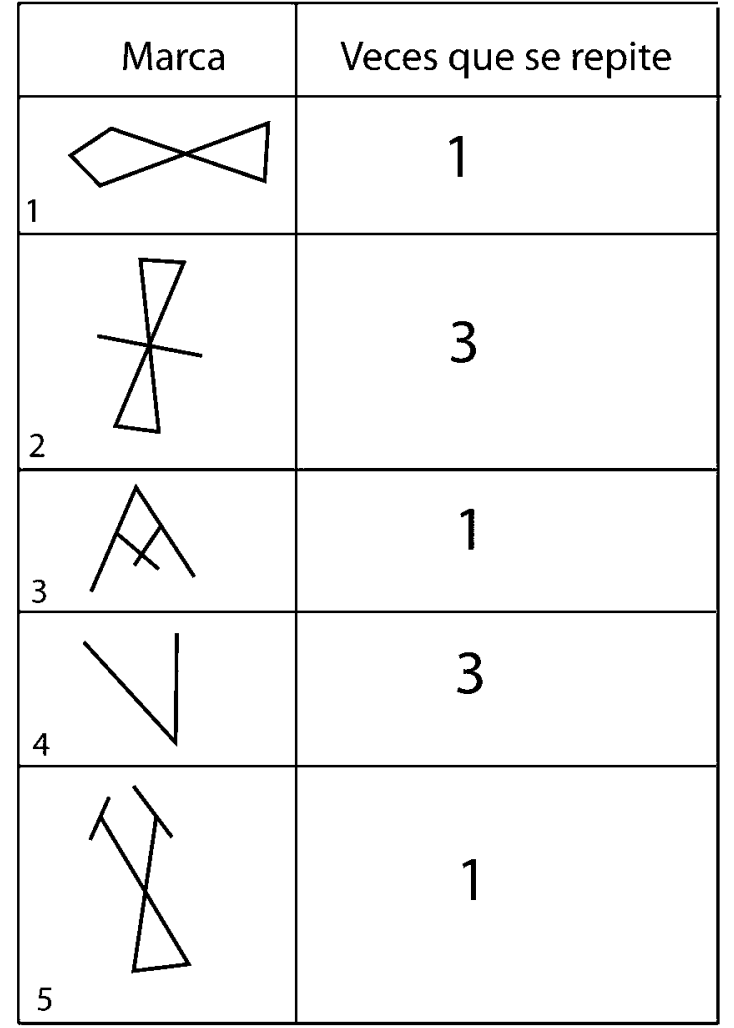

Fig. 5. Marcas en la zona I.

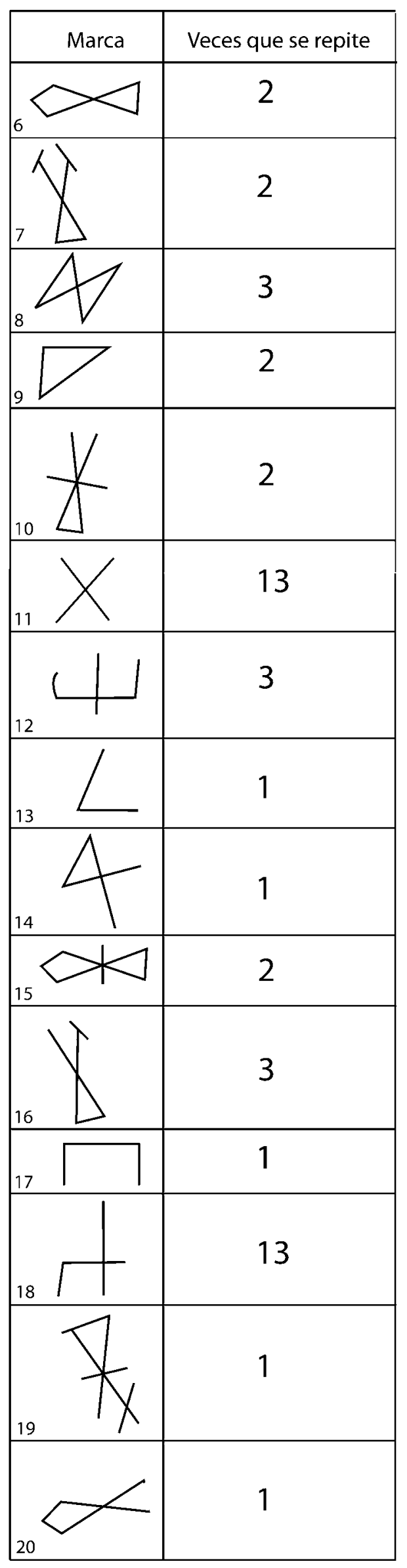

Fig. 6. Marcas en la zona 2 


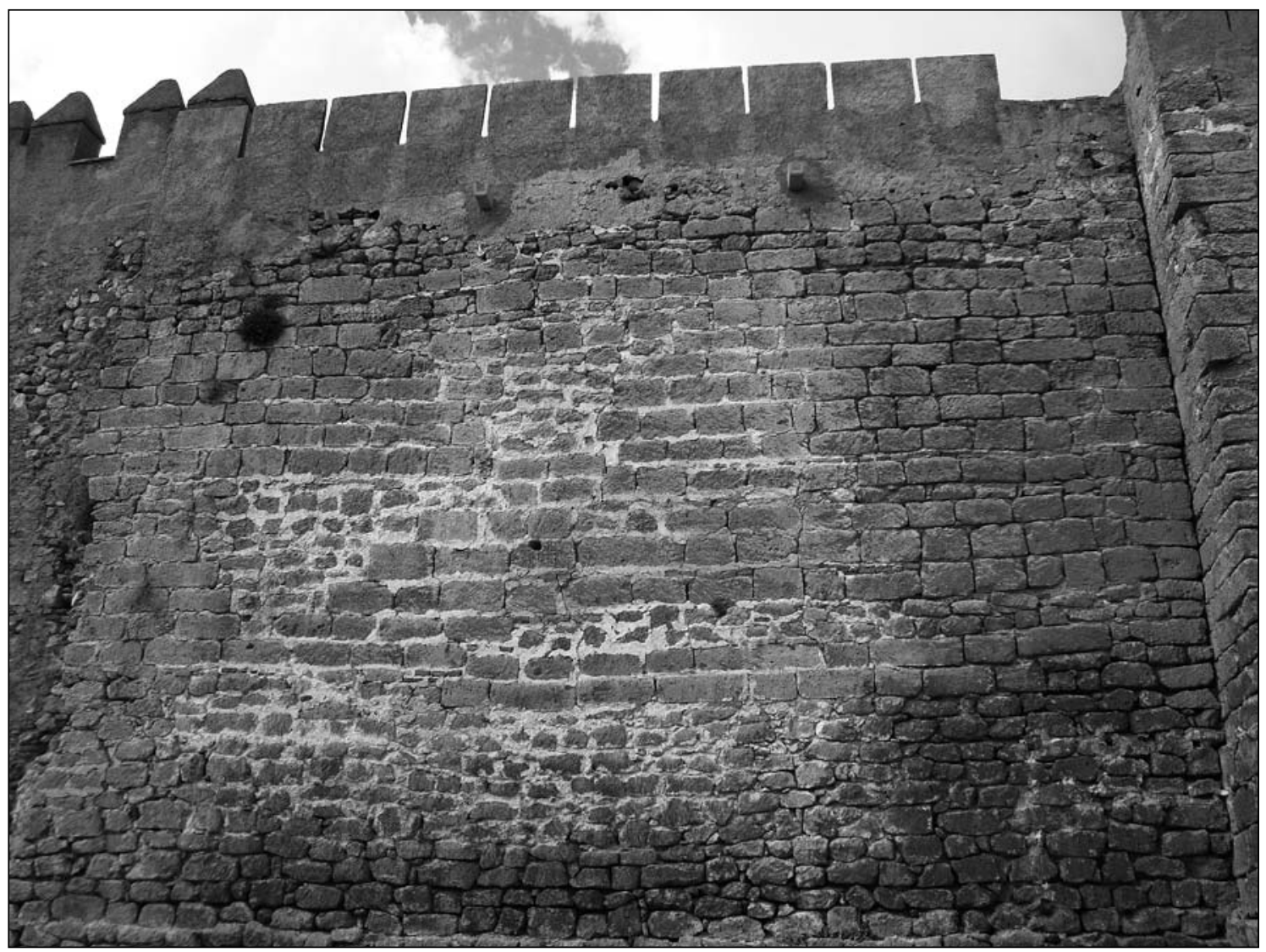

Fig. 7. Paño del muro de la Vela.

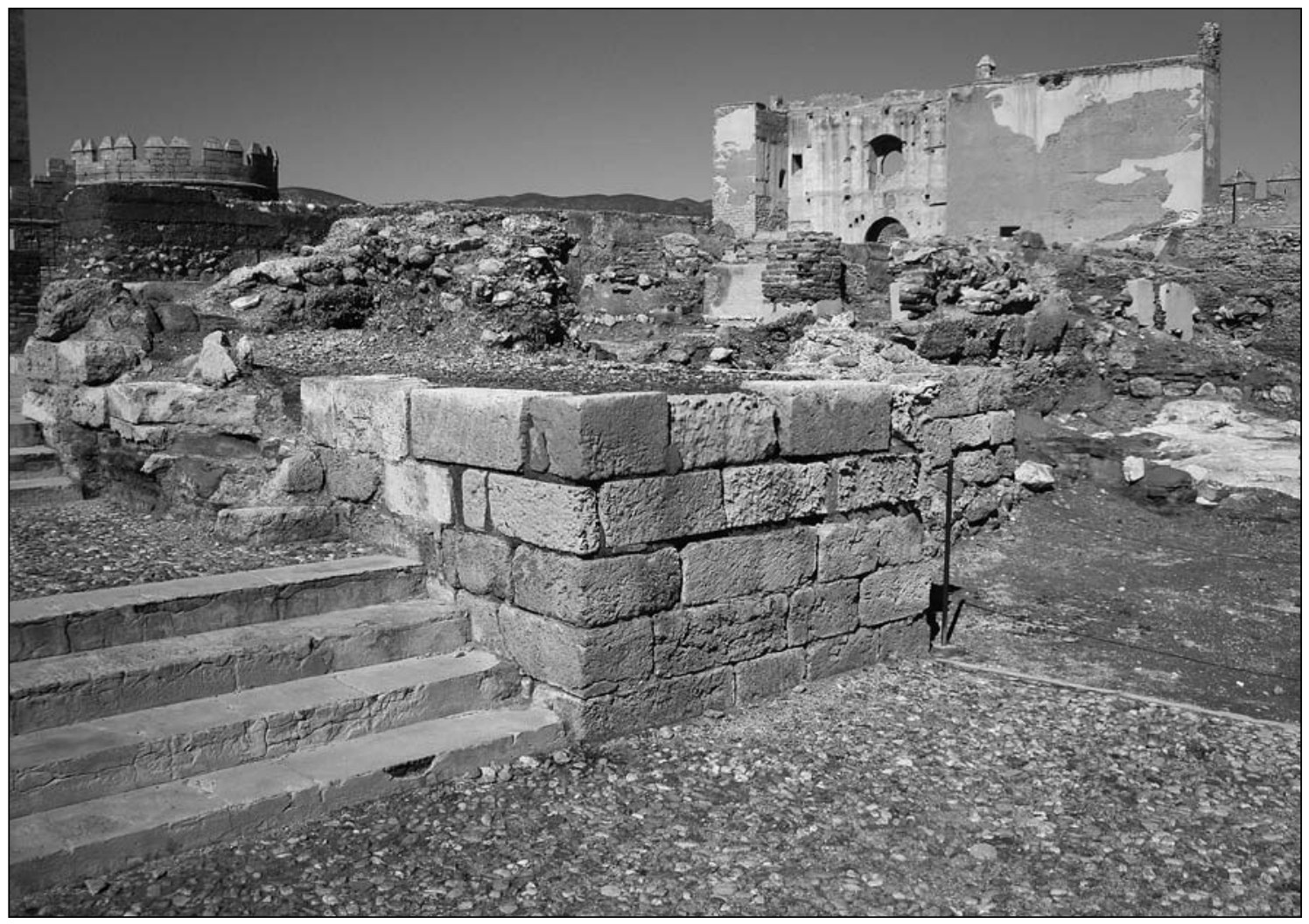

Fig. 8. Machón de sillería en el segundo recinto 


\begin{tabular}{|c|c|}
\hline Marca & Veces que se repite \\
\hline 21 & 1 \\
\hline X2 & 1 \\
\hline 1 & 1 \\
\hline
\end{tabular}

Fig. 9. Marcas en la zona 3

Fig. 10. Portada y acceso de la Torre del Homenaje

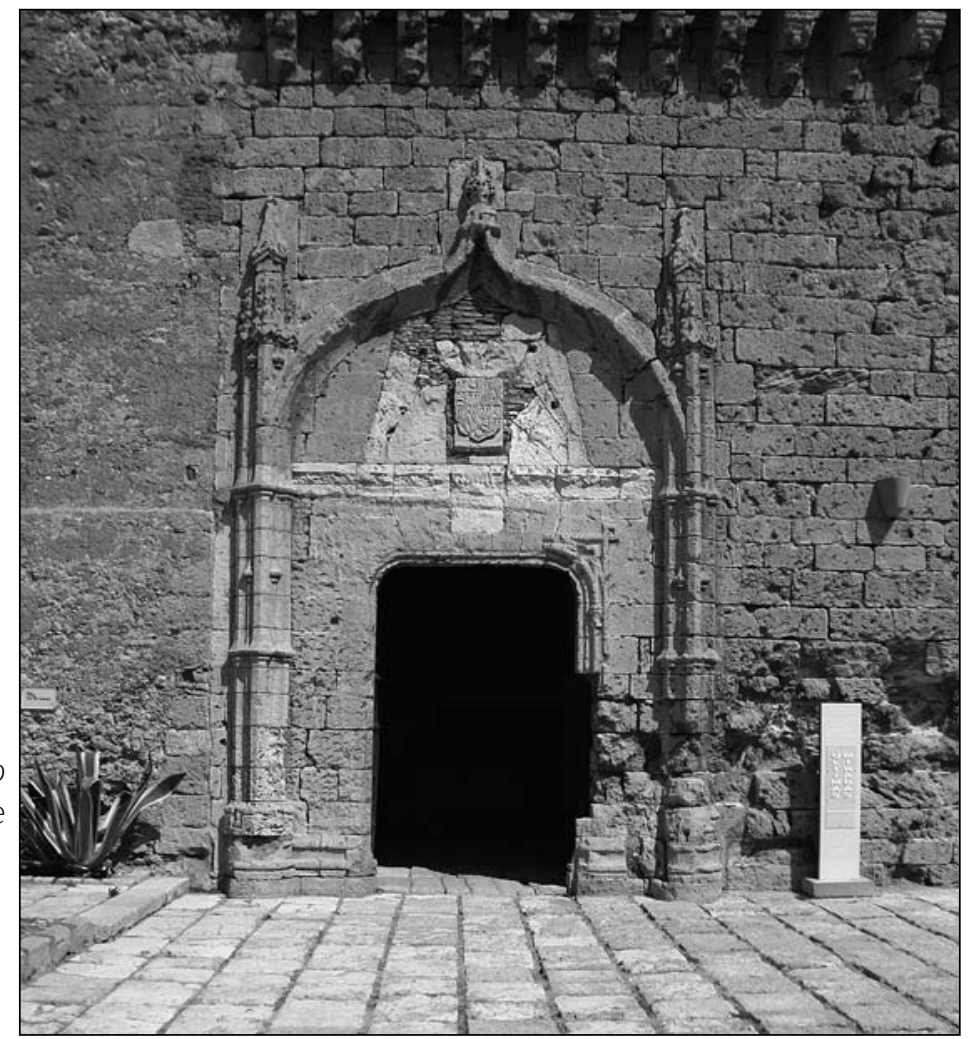

\begin{tabular}{|c|c|c|c|}
\hline Marca & Veces que se repite & Marca & Veces que se repite \\
\hline${ }_{24}>$ & 1 & $\angle$ & 1 \\
\hline 25 & 1 & 34 & 1 \\
\hline 26 & 6 & ${ }_{35} Y$ & 1 \\
\hline 27 & 1 & $\Delta P$ & 1 \\
\hline 28 & 6 & $\square$ & 1 \\
\hline$\square$ & 19 & & 1 \\
\hline${ }_{30}$ & 2 & & 1 \\
\hline 31 & 2 & 40 & 1 \\
\hline 8 & 2 & & $\begin{array}{l}\text { Fig. I I. Marcas } \\
\text { en la zona } 4 .\end{array}$ \\
\hline
\end{tabular}




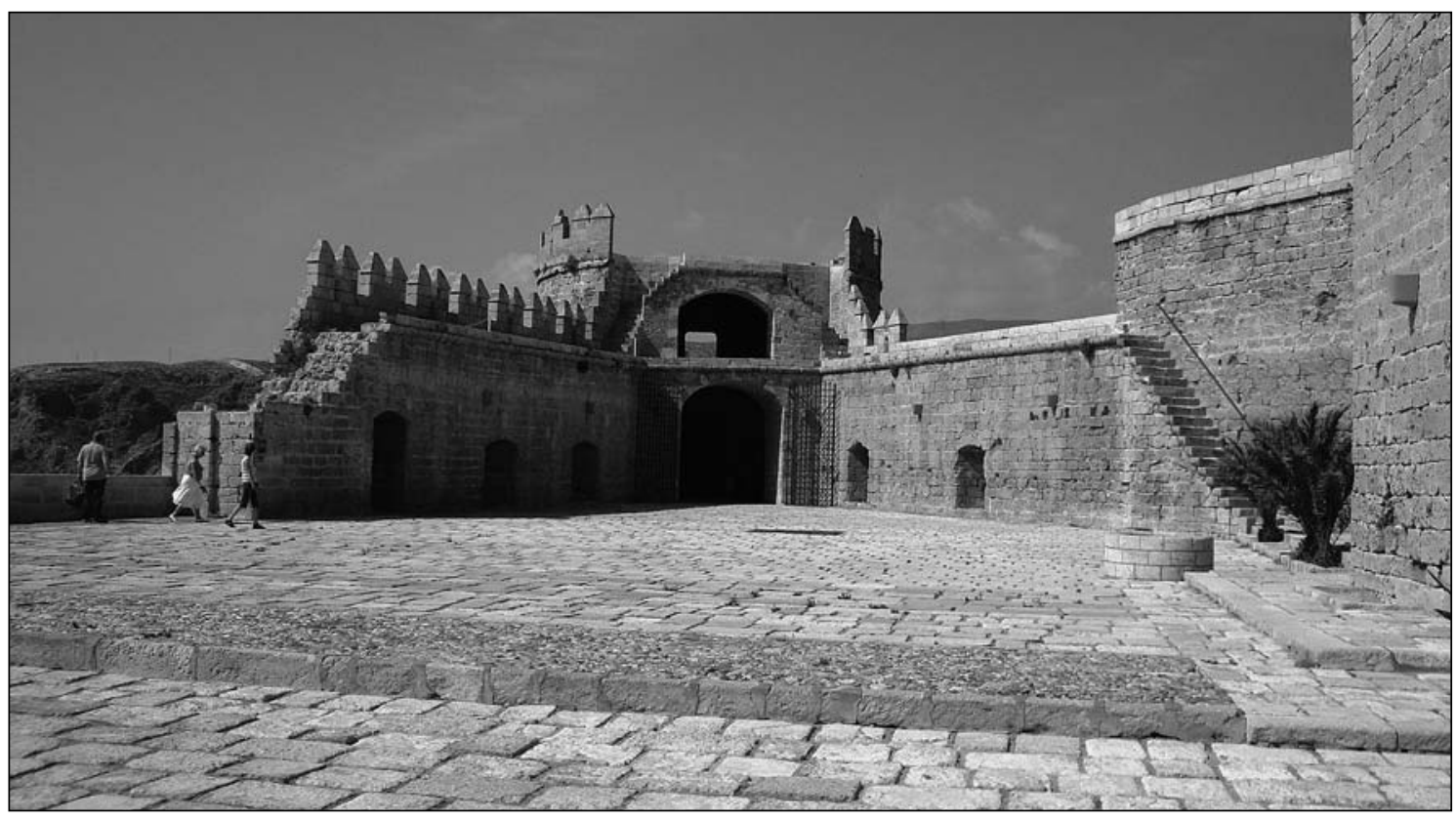

Fig. I 2. Vista de la Torre de la Pólvora y

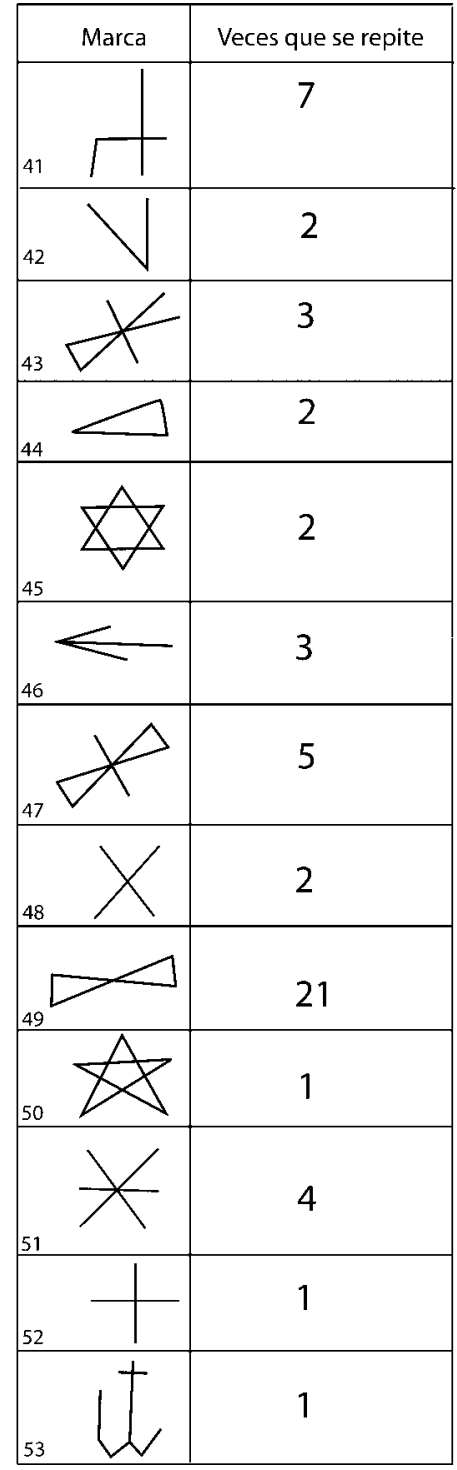

los dos lienzos anexos, desde el extremo opuesto del patio.

Fig. 13. Marcas en la zona 5. 


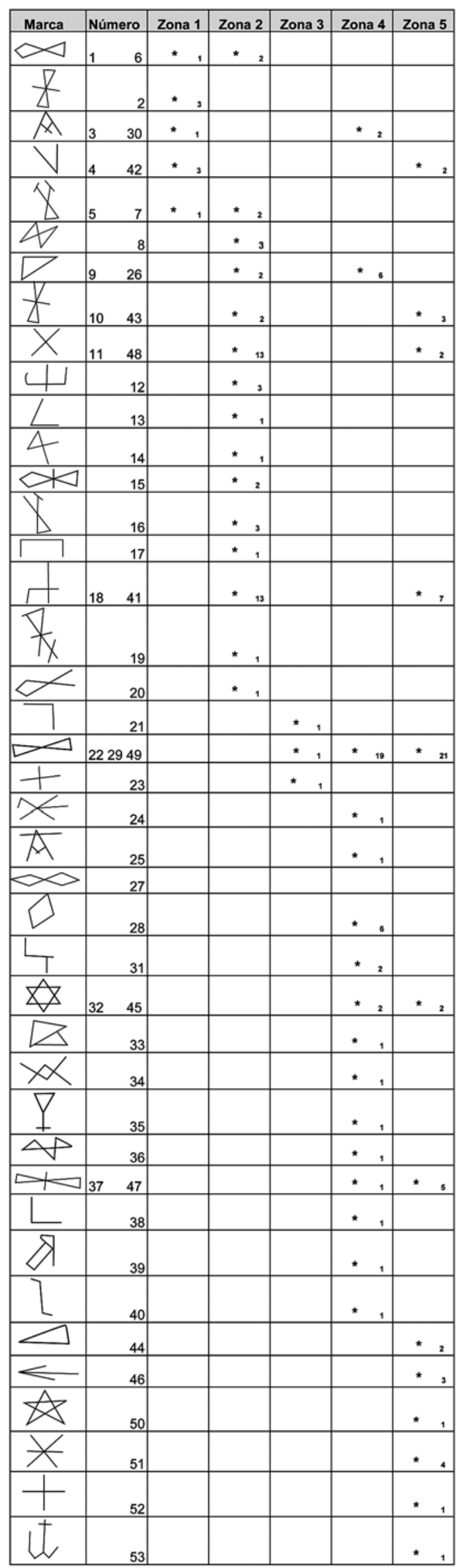

Fig. I4. Cuadro final de todas las marcas numeradas, mostrando las que se repiten en las diferentes zonas y el número de veces. 